\title{
Hepcidin gene expression and biochemical changes in high fat diet induced albino rats
}

\author{
Ingy Badawy* \\ College of Biotechnology, Misr University for Science and Technology, Egypt
}

ARTICLE INFO

Article history:

Received 04 June 2016

Accepted 27 June 2016

Keywords:

Hepcidin;

Iron;

Ferritin;

NAFLD

\begin{abstract}
A B S T R A C T
The regulation of lipid metabolism is one of the liver's core functions. Fatty liver accumulation, inflammatory process and insulin resistance have been involved in the development and progression of non-alcoholic fatty liver disease (NAFLD), however resulting findings pointed an important role also for iron overload and triglyceride accumulation. In this study, we investigate the relative expression of hepcidin in addition to several biochemical parameters in the onset of steatosis to understand whether its impairment could be an early event of liver inflammatory injury. Sixteen rats were divided into two groups eight per each, one group fed with normal diet and the other with high fat diet (HFD) for 6 weeks, after which serum lipid profile, transaminases levels, iron and ferritin were evaluated, in addition to hepcidin mRNA quantitation. In HFD fed rats, an increased serum transaminases levels, triglyceride and iron in comparison with the control group, associated with the increase in hepcidin relative expression and ferritin decreased level. In conclusion, the current study suggests that increased exposure to fatty acids subverts hepatic iron metabolism, favouring the induction of iron and hepcidin expression, so, hepcidin may serve as a marker for better diagnosing and monitoring NAFLD in early stages in order to avoid progression of the disease.
\end{abstract}

\section{Introduction}

High level of caloric intake has been associated with many diet-induced complications, including metabolic syndrome, cardiovascular disease and non-alcoholic fatty liver disease (NAFLD) ${ }^{[1]}$. Non-alcoholic fatty liver disease (NAFLD) encompasses a spectrum of liver disease ranging from simple benign steatosis to nonalcoholic steatohepatitis (NASH) ${ }^{[2,3]}$. The precise mechanisms of non-alcoholic steatohepatitis (NASH) development are not well understood. Although a socalled "two-hit hypothesis" ${ }^{[4]}$ NASH can also expand in the absence of insulin resistance and simple benign steatosis (i.e., initial hit) ${ }^{[5]}$. The potential candidates regarded as the "second hit" include oxidative stress, inflammation and transformation in mitochondrial function ${ }^{[6-10]}$. Iron is also considered as a "second hit" in liver injury ${ }^{[11]}$ and a role for iron has been reported in NASH pathogenesis. Patients with NAFLD/NASH usually display elevated serum iron indices and hepatic iron content ${ }^{[\mathbf{1 2}, 13]}$. Iron disorder is considered one of the serious causes of liver damage ${ }^{[\mathbf{1 4 , 1 5 ]}}$ as its homeostasis is maintained by liver contribution through two major

\footnotetext{
* Corresponding author.

E-mail address: inji.mahmoud@must.edu.eg
}

mechanisms: iron storage and hepcidin hormone secretion. Intracellular endoplasmic reticulum (ER) stress induced by nutrient excess has been shown to stimulate hepcidin expression and leads to hypoferremia in mice ${ }^{[16,17]}$.

It has also been shown that mice fed a high-fat diet undergo sustained hepatic inflammation, which influences hepatic hepcidin expression, resulting in a reduction of the hepatic iron level ${ }^{[18]}$. These reports suggest the possibility that lipid metabolism interacts with iron metabolism. Bile duct ligation was found to reduce the hepatic iron level but pravastatin administration reversibly increased the level, affecting expression of iron metabolism-related genes in the rats [19]. Over nutrition, the central feature of the "modern lifestyle", with carbohydrates, fats or both has a key role in the multiple parallel hits-related to NAFLD. In this study rats fed a high fat diet, representing a model of hepatic steatosis, were used to investigate whether the dysregulation of hepatic iron metabolism in addition to hepcidin expression play a role in the early events of steatosis and inflammation in order to find a relation between impaired iron homeostasis, liver inflammatory damage and ongoing of disease. 


\section{Materials and methods Animal design}

16 albino rats were purchased and housed in the Center of biological experiments and experimental surgery of the faculty of medicine, Cairo university, the rats were divided into two groups:Group I :included 8 rats as control, fed normal diet and group II: included 8 rats fed high fat diet (HFD) rich in saturated and unsaturated fats and low in carbohydrates ( $60 \%$ fats, $20 \%$ carbohydrates and $20 \%$ proteins) for 6 weeks.

\section{Sample collection}

After 6 weeks of high fat diet (HFD), Blood was collected in two ways: In EDTA free tubes, clotted for 30 minutes then centrifuged at $5000 \mathrm{rpm}$ for $10-15$ minutes. The serum was collected and kept at $-20^{\circ} \mathrm{C}$ until used for the biochemical analyses, and in tubes with EDTA for RNA extraction from whole blood.

\section{Biochemical tests}

Aspartate aminotransferase (AST), alanine aminotransferase (ALT) were carried out using Spectrum Kit (E.C.2.6.1.1 and E.C.2.6.1.2, respectively), Albumin, Urea, Creatinine, iron, Total cholesterol and High-density lipoprotein (HDL) were carried out using Biodiagnostic kits for enzymatic colorimetric method, Low-density lipoprotein cholesterol (LDL-C) was calculated as [total cholesterol - HDL-C-triglyceride x 0.2]. Triglyceride (TG) and glucose were carried out using BioSTC Kit, and ferritin was measured using Ferritin-turbidimetric kit from
Linear Chemicals, Spain according to the manufacture's protocol.

\section{Real-time PCR}

Total RNA was extracted from whole blood using the QIAamp RNA Mini Kit Quigen, according to the manufacturer's instructions. cDNA was synthesized using a reverse transcription kit (High capacity cDNA Reverse Transcription Kit, applied Biosystems) from 1 ug total RNA. PCRs were performed using ABIPrism 7500 fast real-time PCR system instrument and software ( Applied Biosystem). The thermal profile was $10 \mathrm{~min}$ at $95^{\circ} \mathrm{C}$ followed by 40 cycles of two-step PCR denaturation at $95^{\circ} \mathrm{C}$ for $15 \mathrm{~s}$ and annealing/extension at $60^{\circ} \mathrm{C}$ for $60 \mathrm{~s}$. Each sample contained $1 \mu \mathrm{g}$ cDNA in $10 \mathrm{ul}$ 2X Power SYBRGreen PCR Master Mix (Applied Biosystem) and 100 pmole of each primer in a final volume of $20 \mu \mathrm{l}$. The analysis of real time PCR output data followed the manufacturer-suggested delta $\mathrm{Ct}$ method. Cycle threasholds $(\mathrm{Ct})$ were measured and the relative expression of hepcidin gene was calculated by comparison of $\mathrm{Ct}$ values, using one calibrating sample from the control group. All samples were normalized to the housekeeping gene, glyceraldehyde-3-phosphate dehydrogenase (GAPDH). Melt curve analysis was used to confirm the production of a single amplicon for each gene tested. The $\Delta \mathrm{Ct}$ for each sample was determined using the equation $\Delta \mathrm{Ct}=\mathrm{Ct}$ target gene $-\mathrm{Ct}$ reference gene to calculate the relative expression of each gene to the internal reference control ${ }^{[20]}$.

\section{List of primers used for quantitative real time PCR:}

$\begin{array}{ll}\text { Target Gene } & \text { Forward Primer }\left(\mathbf{5}^{\prime}-\mathbf{3}^{\prime} \text { ) }\right. \\ \text { GAPDH } & \text { AGATCCACAACGGATACATT } \\ \text { Hepcidin } & \text { GAAGGCAAGATGGCACTAAGCA }\end{array}$

\author{
Reverse Primer (5'-3') \\ TCCCTCAAGATTGTCAGCAA \\ TCTCGTCTGTTGCCGGAGATAG
}

\section{Statistical analysis}

Data were analyzed using SPSS (Statistical Program for Social Science version 17). Quantitative variables were described as mean, SD. The NPAR TESTS was used to compare quantitative variables between groups. The Mann-Whitney test was used instead of the unpaired ttest for nonparametric data,

Spearman correlation coefficient test was used to rank variables positively or negatively.

$P$ values greater than 0.05 were considered insignificant; $P$ values less than 0.05 were considered significant; and $\mathrm{P}$ values less than 0.01 were considered highly significant.

\section{Results}

\section{Effect of high fat diet on the biochemical parameters}

Rats subjected to HFD show no significant difference in comparison with the control group regarding albumin, creatinine, Total cholesterol, HDL, LDL and glucose as $\mathrm{P}$ value was more than 0.05 (Table 1).

The mean values of serum ALT and AST were significantly higher among HFD group (19.66 \pm 1.65 and
$7.1 \pm 0.42$ respectively) compared with control group (8.38 \pm 0.63 and $5.06 \pm 0.76$, respectively) with $\mathrm{P}<0.05$, the mean values of Triglyceride (TG), Iron and urea were significantly higher among HFD group (133.38 \pm 17.98 , $264.88 \pm 40.87$ and48.3 \pm 3.85 respectively) compared with control group $(107.63 \pm 36.53,186.88 \pm 41.69$ and $34.29 \pm 4.97$ respectively) as shown in Table 1 .

Our results show a positive significant correlation between the ALT and iron in HFD group while there is a negative correlation between ALT and ferritin and show a positive significant correlation between the AST and iron in HFD group while there is a negative correlation between AST and ferritin (Table 2 \& Figs. 1\&2).

Effect of High Fat Diet on the Hepcidin expression

The $\Delta \mathrm{Ct}$ for each sample was determined using the equation $\Delta \mathrm{Ct}=\mathrm{Ct}$ target gene $-\mathrm{Ct}$ reference gene to calculate the relative expression of Hepcidin gene to the internal reference control (GAPDH), the results show a relative expression of Hepcidin in both groups with higher value of $\triangle \mathrm{CT}$ relative expression in HFD group than the control group $(-5.51 \pm 4.31$ and $-7.57 \pm 0.8$, respectively). 
Table 1: Comparison between the HFD group and control regarding the biochemical parameters.

\begin{tabular}{lccc}
\multicolumn{1}{c}{ Parameters } & $\begin{array}{c}\text { Control group } \\
\mathbf{N = 8}\end{array}$ & $\begin{array}{c}\text { HFD group } \\
\mathbf{N = 8}\end{array}$ & Test of significance \\
\hline ALT (U/L) & $8.38 \pm 0.63$ & $19.66 \pm 1.65$ & $\mathrm{Z}=-3.37, \mathrm{P}=0.001$ \\
AST (U/L) & $5.06 \pm 0.76$ & $7.1 \pm 0.42$ & $\mathrm{Z}=-3.37, \mathrm{P}=0.001$ \\
ALB (g/dl) & $4.06 \pm 0.46$ & $4.38 \pm 0.16$ & $\mathrm{Z}=-1.49, \mathrm{P}=0.136$ \\
Creatinine (mg/dl) & $0.64 \pm 0.03$ & $0.65 \pm 0.04$ & $\mathrm{Z}=-0.48, \mathrm{P}=0.635$ \\
T.Chol (mg/dl) & $63.88 \pm 12.65$ & $70.5 \pm 5.61$ & $\mathrm{Z}=-0.84, \mathrm{P}=0.399$ \\
TG (mg/dl) & $107.63 \pm 36.53$ & $133.38 \pm 17.98$ & $\mathrm{Z}=-2.42, \mathrm{P}=0.015$ \\
HDL (mg/dl) & $11.63 \pm 1.98$ & $11.66 \pm 1.53$ & $\mathrm{Z}=-0.21, \mathrm{P}=0.833$ \\
LDL (mg/dl) & $29.41 \pm 9.55$ & $34.75 \pm 6.6$ & $\mathrm{Z}=-1.26, \mathrm{P}=0.207$ \\
Iron (umol/L) & $186.88 \pm 41.69$ & $264.88 \pm 40.87$ & $\mathrm{Z}=-2.85, \mathrm{P}=0.004$ \\
Ferritin (ug/L) & $6.09 \pm 0.85$ & $5.06 \pm 0.37$ & $\mathrm{Z}=-2.11, \mathrm{P}=0.035$ \\
Glucose (mg/dl) & $111 \pm 6.66$ & $118.13 \pm 11.74$ & $\mathrm{Z}=-1.58, \mathrm{P}=0.113$ \\
Urea (mg/dl) & $34.29 \pm 4.97$ & $48.3 \pm 3.85$ & $\mathrm{Z}=-3.16, \mathrm{P}=0.002$ \\
\hline
\end{tabular}
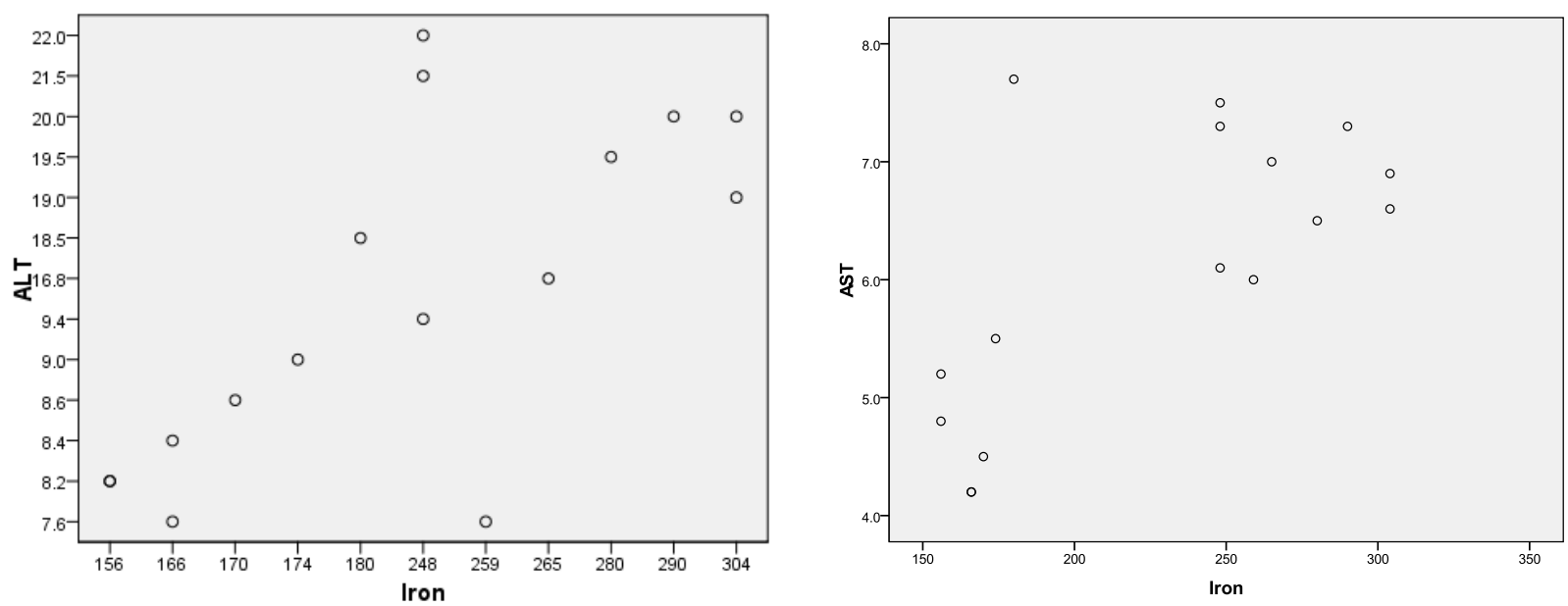

Fig. (1): Correlation between transaminase enzymes (ALT \&AST) and Iron.
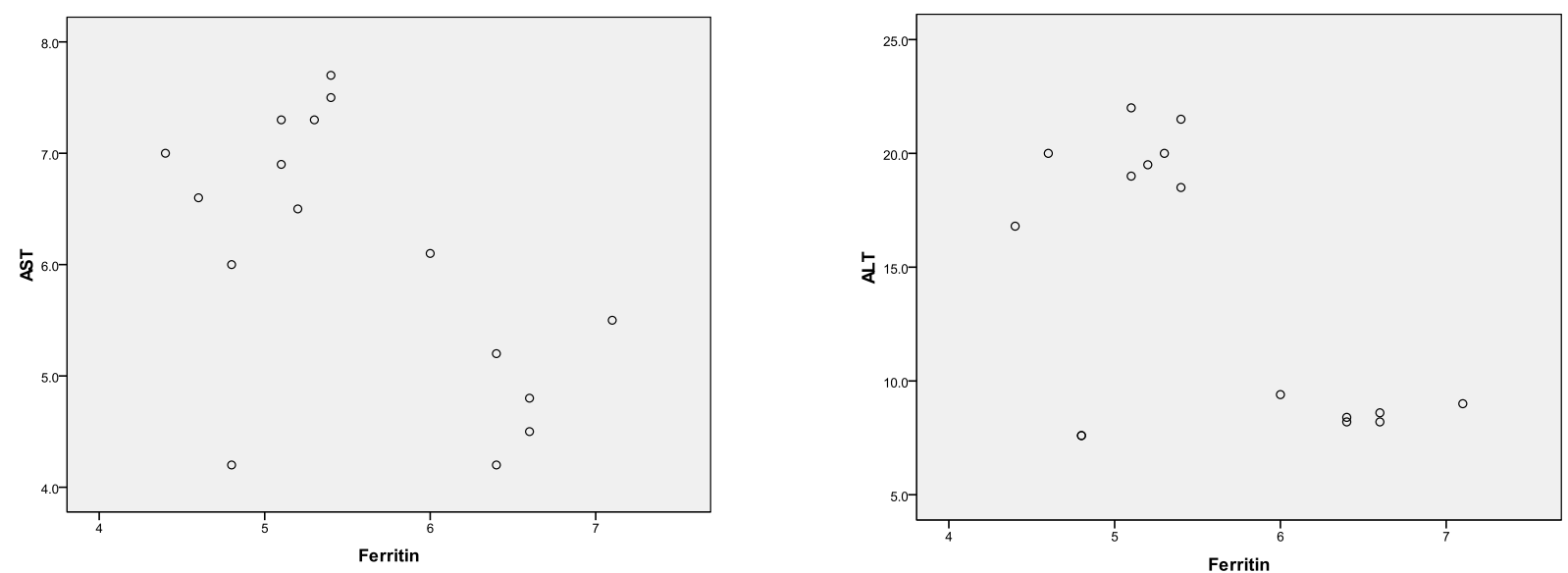

Fig. (2): Correlation between transaminase enzymes (ALT \&AST) and Ferritin. 
Table 2: Correlation between ALT, AST, iron and both iron and ferritin.

\begin{tabular}{|c|c|c|}
\hline & $\begin{array}{c}\text { Iron } \\
\text { Sig.(2-tailed) }\end{array}$ & $\begin{array}{c}\text { Ferritin } \\
\text { Sig. }(2 \text {-tailed })\end{array}$ \\
\hline ALT & $0.002^{* *}$ & $0.023^{*}$ \\
\hline $\mathbf{A S T}$ & $0.003^{* *}$ & $0.029^{*}$ \\
\hline Iron & - & $0.006^{* *}$ \\
\hline
\end{tabular}

\section{Discussion}

Iron overload could induce liver injury [21]. Since hepcidin is the master regulator of iron hemostasis, response of hepcidin to iron change is more sensitive specially when occurs with liver injury. Based on our observation, the HFD group show a significant increase in iron accompanied with a relative hepcidin expression. In contrast, some studies have reported a reduction in hepcidin level in some clinical patients with liver diseases [22-24]. One plausible reason is that the regulation of hepcidin in liver injury is complicated, and may vary according to the nature or severity of the damage for some liver diseases with increased transaminases serum level, such as chronic hepatitis $\mathrm{C}$ ${ }^{[24]}$ and alcoholic liver diseases ${ }^{[25]}$. Among the hepatic enzymes, ALT is most closely related to liver fat accumulation ${ }^{[26]}$. Our results agree with the findings of previous studies showing the elevated ALT concentration as an independent predictor of incident non alcoholic fatty liver disease (NAFLD) ${ }^{[27]}$. This finding could be explained by the higher specificity of ALT for liver injury ${ }^{[26]}$. Also, as a gluconeogenic enzyme ${ }^{[27]}$, increased ALT has been demonstrated to be an indicator of impaired insulin signalling, which might not necessarily be associated with liver injury due to hepatic steatosis ${ }^{[28,29]}$. In our study the liver function enzymes (AST and ALT) were significantly increased in HFD group as compared with control group meaning that there is a liver injury or inflammation which may be because of the iron-driven free radical production (Table 1).

In HFD fed rats group we found a significant increase in the iron as compared with control group (264.88 \pm 40.87 and $186.88 \pm 41.69$ respectively) while there were a significant decrease in ferritin level between the two groups, these findings were proposed of an increased iron uptake into hepatocytes, which could lead to an increase of harmful free-iron since ferritin content was decreased. The limited iron-storage capacity makes the cells susceptible to iron-catalyzed reactive oxygen species (ROS) damage, contributing to the progression of liver damage. As a rule, the increase of intracellular iron decreases Iron regulatory protein-1(IRP1) binding activity, while other factors are able to regulate this activity, including oxidative stress ${ }^{[30]}$. Moreover, the reduction of ferritin biosynthesis due to the activation of IRP1 by oxidative stress is well documented ${ }^{[30,31]}$, and our results stick to these findings.

However, under conditions of oxidative stress, the early degradation of liver ferritin contributes to expand the intracellular free iron pool that, later on, activates multiple molecular mechanisms to reconstitute ferritin content ${ }^{[32]}$. Kowdley et al ${ }^{[33]}$ examined in human the relationship between elevated serum ferritin and NAFLD severity. They showed that serum ferritin can be considered a marker in identifying patients with NAFLD who are at increased risk of more advanced disease, even among patients without hepatic iron deposition, this is in agreement with our results .Other recent studies report alterations of iron metabolism in HFD fed animals. In a mouse model of diet-induced obesity without inflammation the authors evidenced a decreased serum and tissue iron and an increased serum ferritin while this results are in contrast with our results which show an increase in the iron level and decrease in ferritin level in HFD rats compared with the control group (Tables 1\&2).In this study an increase in hepatic iron and related oxidative stress together with an increase in the relative expression of hepcidin in addition to triglyceride increased level in HFD group serum may be used as a marker for steatosis. However, many other studies are confirmed with our results evidencing a significant increase in hepcidin associated to inflammation and often to hypoferremia ${ }^{[34,35]}$. Taken all together, our data clearly show an early impairment of iron metabolism in the initial stage of steatosis contributing to the progression of the disease and the concept of "multiple hits" in the progression of inflammation in NAFLD ${ }^{[36]}$.

\section{Conclusion}

The results show that it is useful to use the combination between the increased level of aminotransaminase enzymes in addition to both the iron and hepcidin level as predictive markers of liver inflammation or injury due to fatty diet in order to prevent the prognosis of the disease to NAFLD, and due to the small samples size, a larger randomized study should be carried out in the future.

\section{References}

1) Massiera, F., Barbry, P., Guesnet, P., Joly, A., Luquet, S., Moreilhon-Brest, C., Mohsen-Kanson, T., Amri, E. Z. and Ailhaud, G. (2010). A Western-like fat diet is sufficient to induce a gradual enhancement in fat mass over generations. J Lipid Res., 51:2352-2361. 
2) Anstee, Q. M., Targher, G. and Day, C. P. (2013). Progression of NAFLD to diabetes mellitus, cardiovascular disease or cirrhosis. Nat Rev Gastroenterol Hepatol., 10:330-344.

3) Brunt, E. M., Janney, C. G., Di Bisceglie, A. M., Neuschwander-Tetri, B. A. and Bacon, B. R. (1999). Nonalcoholic steatohepatitis: a proposal for grading and staging the histological lesions. Am J Gastroenterol., 94:2467-2474.

4) Day, C. P. and James, O. F. (1998). Steatohepatitis: a tale of two "hits"? Gastroenterology., 114:842-845.

5) Tiniakos, D. G., Vos, M. B. and Brunt, E. M. (2010). Nonalcoholic fatty liver disease: pathology and pathogenesis. Annu Rev Pathol., 5:145-171.

6) Basaranoglu, M., Basaranoglu, G. and Sentürk, H. (2013). From fatty liver to fibrosis: a tale of "second hit". World J Gastroenterol., 19:1158-1165.

7) Malaguarnera, M., Di Rosa, M., Nicoletti, F. and Malaguarnera, L. (2009). Molecular mechanisms involved in NAFLD progression. J Mol Med (Berl)., 87:679-695.

8) Takaki, A., Kawai, D. and Yamamoto, K. (2013). Multiple hits, including oxidative stress, as pathogenesis and treatment target in non-alcoholic steatohepatitis (NASH). Int J Mol Sci., 14:2070420728.

9) Dowman, J. K., Tomlinson, J. W. and Newsome, P. N. (2010). Pathogenesis of non-alcoholic fatty liver disease. QJM., 103:71-83.

10) Fabbrini, E., Sullivan, S. and Klein, S. (2010). Obesity and nonalcoholic fatty liver disease: biochemical, metabolic, and clinical implications. Hepatology., 51:679-689.

11) O'Brien, J. and Powell, L. W. (2012). Nonalcoholic fatty liver disease: is iron relevant? Hepatol Int., 6:332-341.

12) Martinelli, N., Traglia, M., Campostrini, N., Biino, G., Corbella, M., Sala, C., Busti, F., Masciullo, C., Manna, D., Previtali, S., Castagna, A., Pistis, G., Olivieri, O., Toniolo, D., Camaschella, C. and Girelli, D. (2012). Increased serum hepcidin levels in subjects with the metabolic syndrome: a population study. PLoS One., 7:e48250.

13) Aigner, E., Weiss, G. and Datz, C. (2015). Dysregulation of iron and copper homeostasis in nonalcoholic fatty liver. World J Hepatol., 7:177188.

14) Powell, E. E., Ali, A., Clouston, A. D., Dixon, J. L., Lincoln, D. J., Purdie, D. M., Fletcher, L. M., Powell, L. W. and Jonsson, J. R. (2005). Steatosis is a cofactor in liver injury in hemochromatosis. Gastroenterology, 129, 1937-1943.

15) Adams, P. C., Reboussin, D. M., Barton, J. C., Mclaren, C. E., Acton, R. T., Harris, E. L., Gordeuk, V. R., Leiendecher-foster, C., Speechley, M., Snively, B. M., Holup, J. L., Thomson, E. and Sholinsky, P. (2005). Hemochromatosis and iron-overload screening in a racially diverse population. $\mathrm{N}$ Engl J Med., 352: 1769-1778.
16) Vecchi, C., Montosi, G., Zhang, K., Lamberti, I., Duncan, S. A., Kaufman, R. J. and Pietrangelo, A. (2009). ER stress controls iron metabolism through induction of hepcidin. Science, 325:877-880.

17) Oliveira, S. J., Pinto, J. P., Picarote, G., Costa, V. M. Carvalho, F., Rangel, M., de Sousa, M. and de Almeida, S. F. (2009). ER stress-inducible factor CHOP affects the expression of hepcidin by modulating C/EBPalpha activity. PLoS One, 4: doi:10.1371/journal.pone.0006618.

18) Chung, J., Kim, M. S. and Han, S. N. (2011). Dietinduced obesity leads to decreased hepatic iron storage in mice. Nutr Res., 31:915-921.

19) Kolouchova, G., Brcakova, E., Hirsova, P., Cermanova, J., Fuksa, L., Mokry, J., Nachtigal, P., Lastuvkova, H. and Micuda, S. (2011). Modification of hepatic iron metabolism induced by pravastatin during obstructive cholestasis in rats. Life Sci., 89:717-724.

20) Schmittgen, T. D. and Livak, K. J. (2008). Analyzing real-time PCR data by the comparative CT method. Nature Protocols, 3(6):1101-1108.

21) Roheeth, D. D., Anita, C. G., Janina, E. E., Tirnitz, P., Eng, K. G., Kevin, D. C., Ross, M. G., John, K. O. and Debbie T (2012). Disruption of hemochromatosis protein and transferrin receptor 2 causes iron-induced liver injury in mice. Hepatology, 56:585-593.

22) Miura, K., Taura, K., Kodama, Y., Schnabl, B. and Brenner, D. A. (2008). Hepatitis C virusinduced oxidative stress suppresses hepcidinexpression through increased histone deacetylase activity. Hepatology, 48:1420-1429 .

23) Nishina, S., Hino, K., Korenaga, M., Vecchi, C., Pietrangelo, A., Mizukami, Y., Furutani, T., Sakai, A., Okuda, M., Hidaka, I., Okita, K. and Sakaida, I. (2008). Hepatitis C virus-induced reactive oxygen species raise hepatic iron level in mice by reducing hepcidintranscription. Gastroenterology, 134:226-238 .

24) Girelli, D., Pasino, M., Goodnough, J. B., Nemeth, E., Guido, M., Castagna, A., Busti, F., Campostrini, N., Martinelli, N., Vantini, I., Corrocher, R., Ganz, T. and Fattovich, G. (2009). Reduced serum hepcidin levels in patients with chronic hepatitis C. Journal of Hepatology, 51(5):845-852.

25) Corradini, E. and Pietrangelo, A. (2012). Iron and steatohepatitis. J Gastroenterol Hepatol., 27(2):4246.

26) Kim, C. H., Park, J. Y., Lee, K. U., Kim. J. H. and Kim, H. K. (2009). Association of serum gammaglutamyltransferase and alanine aminotransferase activities with risk of type 2 diabetes mellitus independent of fatty liver. Diabetes Metab Res Rev., 25:64-69.

27) Lee, D. H. and Jacobs, D. R. (2005). Association between serum gamma-glutamyltransferase and Creactive protein. Atherosclerosis., 178:327-330.

28) Kang, Y. H., Min, H. K., Son, S. M., Kim, I. J. and Kim, Y. K. (2007). The association of serum gamma 
glutamyltransferase with components of the metabolic syndrome in the Korean adults. Diabetes Res ClinPract. ,77:306-313.

29) Lee, M. Y., Koh, S. B., Koh, J. H., Nam, S. M., Shin, J. Y., Shin, Y. G., Kong, I. D., Ryu, S. Y., Park, J. K. and Chung, C. H. (2008). Relationship between gamma-glutamyltransferase and metabolic syndrome in a Korean population. Diabet Med., 25:469-475.

30) Pantopoulos, K., Mueller, S., Atzberger, A., Ansorge, W., Stremmel, W. and Heentze, M. W. (1997). Differences in the regulation of iron regulatory protein-1 (IRP-1) by extra- and intracellular oxidative stress. J Biol Chem., 272: 9802-9808.

31) Recalcati, S., Minotti, G. and Cairo, G. (2010). Iron regulatory proteins: from molecular mechanisms to drug development. Antioxid Redox Signal, 13:1593-1616.

32) Cairo, G., Tacchini, L., Pogliaghi, G., Anzon, E., Tomasi, A. and Aldo, B. (1995). A Induction of ferritin synthesis by oxidative stress. Transcriptional and post-transcriptional regulation by expansion of the "free" iron pool. J Biol Chem., 270:700-703.

33) Kowdley, K. V., Belt, P., Wilson, L. A., Yeh, M. M., Neuschwander-Tetri, B. A., Chalasani, N., Sanyal, A. J. and Nelson, J. E. (2012). Serum ferritin is an independent predictor of histologic severity and advanced fibrosis in patients with nonalcoholic fatty liver disease. Hepatology, 55:7785.

34) Nicolas, G., Chauvet, C., Viatte, L., Danan, J. L., Bigard, X., Devaux, I., Beaumont, C., Kahn, A. and Vaulont, S. (2002). The gene encoding the iron regulatory peptide hepcidin is regulated by anemia, hypoxia, and inflammation. J Clin Invest., 110:10371044.

35) Sharma, S., Nemeth, E., Chen, Y. H., Goodnough, J., Huston, A., Roodman, G. D., Tomas, G. and Alan, L. (2008). Involvement of hepcidin in the anemia of multiple myeloma. Clin Cancer Res., 14:3262-3267.

36) Tilg, H. and Moschen, A. R. (2010). Evolution of inflammation in nonalcoholic fatty liver disease: the multiple parallel hits hypothesis. Hepatology, 52:1836-1846. 